\title{
Discriminação Histológica entre Displasia Fibrosa Monostótica, Fibroma Ossificante e Fibroma Cementificante*
}

\section{RESUMO}

Foi realizado um estudo histométrico comparativo entre Displasia Fibrosa, Fibroma Ossificante e Fibroma Cementificante, com base em seis casos para cada lesão, os quais tinham diagnósticos clínicos, radiográficos e histológicos confirmados.

O objetivo principal era estabelecer diferenças que permitissem realizar de forma objetiva o diagnóstico histológico. Para isso foram analisadas variáveis relacionadas com o tecido conjuntivo fibroso e o tecido mineralizado; foram estabelecidos índices considerando as relações entre alguns dos parâmetros analisados.

Se pode observar na Fibroma Ossificante, que as células do tecido conjuntivo fibroso tem uma tendência a transformar-se em célula geradoras de matriz orgânica mineralizada. A Displasia Fibrosa demonstrou uma marcada relação entre a presença de vasos sangüíneos e zonas de hemorragia, além de ser comprovada a presença de osteoblastos rodeando as trabéculas mineralizadas, o que é negado por alguns autores para esta lesão.

O fibroma Cementificante apresenta matriz orgânica não mineralizada com uma área maior que na
Displasia Fibrosa e no Fibroma Ossificante, possivelmente por ter uma mineralização mais lenta. Apresentou também uma menor quantidade de células em seu interior.

A variável mais confiável para diferenciar as três lesões entre si, é a forma das trabéculas, predominando os "cementículos" no Fibroma Cementificante, "caracteres chineses" na Displasia Fibrosa e as trabéculas retangulares no Fibroma Ossificante.

\section{SUMMARY}

Based on the histometric anali$z$ is of 18 Fibro osseous lesions, was possible to stablish differences among Fibrous Displasia, Ossifying Fibroma, and Cementy fying Fibroma. The shape of mineralized trabeculae represent the most usefull variable to distinguish these lesion on histopatologic grounds.

\section{INTRODUÇÃO}

As lesões Fibro-6sseas dos Maxilares são um grupo de alterações que tem como característica comum a substituição do tecido osseo normal por um tecido conjuntivo, no qual, vê-se a formação de trabéculas mineralizadas que podem corresponder a osso ou a cemento $(1,8,26$, $44,51,66,67,68,69,70$ ).

É possivel encontrar estas caracteristicas em um grande número de lesões, entre as quais se pode mencionar: a Displasia Fibrosa, o Fibroma Cementificante, o Fibroma Ossificante, o Osteoblastoma, o Osteoma-Osteoide, o Nódulo Cementário Esclerótico, a Osteite Condensante e outras $(1,2,6,7,8,10,11$, $12,13,15,17,18,19,25,26,27,28$, $29,30,31,34,36,37,38,40,41,43$, $44,45,46,48,51,53,54,58,61,62$, $64,65,66,70,71,72$ ).

Estas representam um conjunto de entidades patológicas que tem uma origem tissular e anatômica diferente, já que, algumas derivam do tecido ósseo propriamente dito e outras possivelmente das células do ligamento periodontal que tem a capacidade de diferenciar-se funcionalmente para a produção de cemento. Além disso, sua natureza pode ser

\footnotetext{
*Tese apresentada para a obtenção do tftulo de Magister en Ciencias Odontologicas con mencion en Patologia Oral, na Fac. de Odontologia da U. de Chile em 1987.

* Prof. de Patologia Bucal das Fac. de Odontologia da UFRGS e PUCRS.
} 
distinta, ao encontrar-se entre elas algumas que são de origem neoplásica, reacional ou genética $(13,52$, $69,70)$.

Entre as lesões Fíbro- 6 sseas dos Maxilares existem três, que estão entre as mais predominantes, que apresentam dificuldades em seu diagnóstico diferencial, apesar de possuirem algumas características particulares em seus aspectos clínicos, radiológicos e histológicos. São elas: a Displasia Fibrosa Monostótica, o Fibroma Ossificante e o Fibroma Cementificante $(18,26,28,44$, $55,56,71,72$ ).

Um consenso amplo entre os autores $(18,29,34,37,41,44,51,53$, 70), diz que é imprescindivel para - correto diagnóstico e tratamento das lesões Fibro-ósseas dos Maxilares, realizar a associação dos achados clínicos e radiográficos com a histologia, já que por si, nenhum deles de forma isolada é suficiente para a identificação $(11,18,29,34,44$, $70)$. Desde o ponto de vista histologico se tem conferido a cada uma das lesões Fibro-ósseas dos Maxilares algumas caracteristicas diferenciais, que se baseiam em antecedentes de casos isolados e em um número reduzido de trabalhos, que apresentam grande número de casos. As conclusões estão fundamentadas nas experiências dos autores, 0 que introduz um componente subjetivo bastante grande em suas conclusões e interpretação dos resultados (1, $19,25,26,34,44,66,67,68,69,70$, $71,72)$. Isto leva a confusões e problemas de diagnóstico histológico, já que, os antecedentes estabelecidos não são reproduzíveis.

Além disto, existem discrepâncias entre os Patologistas Bucais e alguns Patologistas Médicos, posto que propõem que não existirlam diferenças entre estas Isões e que são somente expressões da Displasia Fibrosa Monostótica, Schajowicz (55). Porém, para Hammer et al (26) no caso do Fibroma Ossificante e do Cementificante, sua origem estaria no ligamento periodontal, o que Ihe daria característica diferente da Displasia Fibrosa. Esta opinião é compartilhada por outros autores $(1,19$, $34,40,44,50,51,52,53,56,66,70)$. As células periodontais teriam uma linha ontogenética comum, que daria origem aos fibroblastos, osteoblastos, cementoblastos e as células mesenquimáticas indiferenciadas que se encontram nesta estrutura. Portanto, frente a um estímulo poderiam se diferenciar em qualquer um destes tipos celulares, dando lugar a Fibroma Ossificante ou Cementificante $(03,11,44,52,57)$.

A Displasia Fibrosa Monostótica dos Maxilares por sua vez, seria uma lesão central óssea, que pode se apresentar em qualquer osso do esqueleto e que se originaria a partir de fibroblastos $(21,36,48)$.

As dificuldades em efetuar um diagnóstico histológico, derivam da falta de informação objetiva e das discrepâncias de critério entre os autores. Para o presente trabalho se formula a hipótese de que é possivel estabelecer diferenças histológicas entre a Displasia Fibrosa Monostótica, o Fibroma Ossificante e o Fibroma Cementificante, baseando-se no estudo objetivo de parâmetros que podem permitir um diagnóstico discriminante. Para isto é possivel utilizar técnicas de hist ometria para medir as variáveis do tecido conjuntivo fibroso e as estruturas mineralizadas que compõem estas lesões.

\section{REVISÃO DA LITERATURA}

Foram revisadas as caracteristicas de cada uma das lesões em particular e as relaçõese controvérsias que existem entre elas.

\section{Displasia Fibrosa Monostótica dos Maxilares}

A Displasia Fibrosa é uma enfermidade que foi descrita inicialmente por Lichtenstein (36), em sua variante poliostótica, que compromete vários ossos e está associada com problemas endócrinos. É conhecida atualmente como a Síndrome de Albright, que se caracteriza por apresentar manchas escuras na pele e puberdade precoce $(2,29,37,48)$.

Em 1942, Lichtenstein e Jaffe (38), informaram sobre uma forma de Displasia Fibrosa que compromete somente um osso, pelo que foi denominada Monostótica. Esta não é uma fase inicial da variedade poliostótica $(41,60,70)$, mas sim representa uma alteração com caracteristicas próprias. Existem vários estudos sobre as manifestações de Displasia Fibrosa Monostótica nos ossos maxilares, nos quais se analisam suas caractetisticas clínicas e epidemiológicas $(1,6,18,25,51,67)$. É a variedade de Displasia Fibrosa mais freqüente $(24,55,56)$. É uma enfermidade que se apresenta entre os 15 e 25 anos e tem uma leve preferência pelo sexo feminino $(1,6$, $8,24,51,70)$. Produz deformidade facial que pode alcançar tamanhos impressionantes, como nos casos apresentados por Adekeye et al (1). De acordo com a revisão de casos publicados, realizada por Makek (44), se apresenta com quase igual freqüência na mandíbula e na maxila.

O aspecto radiográfico da Displasia Fibrosa é descrito como "imagem de vidro esmerilhado" com limites difusos $(1,6,18,25,51,66,67$, $68,69)$. Waldron (70) chama a atenção sobre o detalhe de que a transição entre a lesão e o osso normal pode apresentar até vários centímetros. Fries (23) demonstra em um estudo que a Displasia Fibrosa pode apresentar-se com distintas imagens em radiografias extra-orais, porém Waldron (70) ressalta que estas variedades são na realidade problemas técnicos e que em radiografias intraorais o aspecto clássico volta a repetir-se.

Os achados histológicos da Displasia Fibrosa mostram um tecido conjuntivo fibroso com fibroblastos jovens, onde se encontram trabéculas de osso irregular, que tendem a adotar a forma de "caracteres chineses" $(44,50)$, não apresentando em sua periferia osteoblastos ativos $(26,51)$. É importante chamar a atenção sobre o fato de que esta estrutura de trabéculas pode trocar nos ossos maxilares e do resto do crâneo $(44,55,60)$ tomando aspectos redondos chamados "corpos psamomas", parecidos com cementículos, como ocorre nos ossos longos (29, $37,70)$.

O tecido conjuntivo pode ser muito vascularizado e apresentar zonas hemorrágicas com hemosside- 
rina. Um elemento de valor no diagnóstico diferencial com outras lesões semelhantes, é a ausência de cápsula ou separação nitida entre 0 tecido lesional e o osso circundante $(44,50)$. Zimermann et al $(72)$, propõe que as recidivas que se apresentam nas Displasias Fibrosas, devem-se a dificuldade em distinguir - limite no momento da intervenção cirúrgica.

\section{Fibroma Ossificante}

Esta lesão foi descrita pela primeira vez em 1927 por Montgomery (46); Phemister e Grimson (49), mais tarde chamaram de Fibro-Osteoma, uma alteração solitária fibro-óssea própria dos maxilares. Kempson (30) em 1966 utilizou o termo Fibroma Ossificante para denominar entidades semelhantes que se apresentam em ossos longos de crianças.

A tualmente o termo mais aceito é Fibroma Ossificante $(7,19,26,27$, $34,50,56$ ).

Langdon et al (34) determinaram que estas lesões são mais freqüentes no sexo feminino e na mandíbula. Hamner et al (26) concordaram com estes achados, porém encontraram uma idade média de 25.8 anos contra 35 , que foi observado por Langdon.

Radiograficamente este tumor pode apresentar um aspecto variado, desde uma imagem radiolúcida, passando por matizes intermediárias, até chegar a ser radiopaca $(7,11$, $26,34,50,70)$. Se pode ver um contorno radiolúcido que representa a cápsula e em certas ocasióes uma linha esclerótica delimitando a lesão $(11,44,50,70)$.

O aspecto histológico do Fibroma Ossificante mostra trabéculas de tecido ósseo rodeadas por osteoblastos ativos, sobre um tecido conjuntivo fibroso. $O$ tecido ósseo pode ser do tipo imaturo, porém se encontram áreas de osso maduro $(6,34$, $44,60,66)$. As trabéculas de osso formadas, apresentam tendência a fusionar-se $(53,60)$. Podem ser encontrados corpos calcificados, de formas arredondadas e basófilos, que lembram cementículos $(61,68$, 70).

A presença de cápsula fibrosa é um elemento de grande importância para o diagnóstico histológico de Fibroma Ossificante $(44,50)$, porém deve ser ressaltado que os achados clínico-radiográficos são mais significativos no estabelecimento do diagnóstico definitivo $(44,70)$.

Em 1952, Smith e Zavaletta (58) descreveram pela primeira vez um caso de Fibroma Ossificante que chamaram "juvenil", por afetar um paciente de 15 anos. Esta é uma lesão mais agressiva e com tendência a recidiva. Waldron (70) descreve que a histologia destas lesões "juvenis" (64) ou "agressivas" $(44,56,70)$ são mais celulares e mostram uma menor proporção de colágeno e tecido ósseo.

\section{Fibroma Cementificante}

Pindborg et al $(50)$ consideram esta lesão como uma forma de $\mathrm{Ce}$ mentoma. Desde o ponto de vista clfnico é uma lesão de crescimento lento, indolor, que abaula as tábuas ósseas, podendo alcançar grandes dimensões $(14,40,56,61)$. Os dentes que estão relacionados com esta alteração podem ser deslocados de sua posição normal $(6,11,50,61)$.

Radiograficamente é uma lesão bem circunscrita que pode variar em sua densidade, desde uma imagem radiolúcida até uma radiopaca (11, $34,44,50,68,70$ ).

Histologicamente vê-se um tecido conjuntivo fibroso, com uma grande quantidade de células, onde se encontra em tecido mineralizado que adapta formas arredondadas, basófilas com linhas incrementais muito marcadas e que lembram cemento secundário ou cementículos $(6,11$, $40,44,50,51,53,56)$. Em certas ocasiões estas podem fusionar-se formando massas calcificadas de maior tamanho, ou encontrar-se trabéculas de tecido ósseo $(8,11,26$, $40,44,66,70)$.

Para Hamner et al (26), esta seria uma lesão com origem no ligamento periodontal, esta idéia é aceita por outros autores $(1,6,11,14$, $27,34,40,44,50,51,56,62,66,67$, $68,70)$. Há evidências que demonstram a presença de fibras oxitalâmicas, as quais estariam em maior quantidade que em outras lesões fibro-ósseas dos maxilares. Estas fibras se encontram normalmente no periodonto $(22,24,27)$. Segundo Reichart e Riess (52) o Fibroma Cementificante tem origem ectomesenquimática, o que permite classificar esta lesão como odontogênica.

\section{ASPECTOS CONTROVERTIDOS E RELAÇÕES ENTRE AS LESỐS}

Alguns autores $(34,41,55)$ pensam que a Displasia Fibrosa Monostótica dos Maxilares e o Fibroma Ossificante, seriam uma mesma lesão, outros $(26,28,51)$, propõem que são de natureza distinta e que tem características clínicas e histológicas próprias.

Schajowicz (55) sustenta que o Fibroma Ossificante seria uma Displasia Fibrosa que poderia apresentar-se como uma variedade histologica distinta nos ossos maxilares. Jaffe (29) em 1958 chamou a atenção sobre o fato de que a Displasia Fibrosa nos ossos maxilares poderia apresentar trabéculas de osso maduro. Esta opinião não é aceita por Hamner et al (26) nem por Reed et al (51), eles afirmam que quando se está frente a uma lesão com características de Displasia Fibrosa e que mostra em sua histologia trabéculas de osso maduro, esta lesão deveria chamar-se Osteoma Fibroso.

Eversole et al (18) e Waldron e Giansanti (67) apresentaram alguns casos em que as caracteristicas cllnicas e radiográficas correspondem a Displasia Fibrosa, porém histologicamente apresentam grande proporção ou em sua totalidade osso maduro. Eles postulam que estas situações com compativeis são o diagnóstico de Displasia Fibrosa.

Se tem proposto que no Fibroma Ossificante as trabéculas de tecido ósseo estão rodeadas de osteoblastos ativos $(26,28,51)$, por outro lado estas células estariam ausentes na Displasia Fibrosa $(36,37,38)$. Esta posição se fundamenta no argumento que o primeiro é um tumor de células formadoras de tecido ósseo, e 0 segundo não tem uma explicação aceitável $(29,37,44,50,56,70)$. Para poder identificar claramente 0 tipo celular se poderia utilizar a microscopia eletrônica, porém segundo 
Alexander (4) é impossivel ultraestruturalmente distinguir um fibroblasto de um osteoblasto inativo.

Outro aspecto controvertido, entre estas duas lesões seria seu crescimento. De acordo com sua natureza tumoral, o Fibroma Ossificante apresenta proliferação indefinida, ao passo que a Displasia Fibrosa teria crescimento limitado estando associado com o período de crescimento do organismo, detendo-se ao final da segunda década de vida. A partir deste momento, o osso imaturo, característico desta lesão, lentamente se substituiria por osso maduro $(7,18,19,26,44,50,70)$.

Um elemento impor tante no diagnóstico diferencial, é o fato de que - Fibroma Ossificante apresenta uma cápsula fibrosa, enquanto que a Displasia Fibrosa, como foi mencionado anteriormente, tem um limite pouco definido.

A tualmente existe uma tendência para considerar o Fibroma Ossificante e o Fibroma Cementificante como uma mesma entidade patológica, devido a suas caracteristicas cllnicas e radiográficas serem semeIhantes e histologicamente ser difícil discriminar o cemento e o tecido ósseo que se produz em cada uma delas $(8,26,34,44,47,51,70)$. Foram realizados vários trabalhos buscando demonstrar as diferenças entre estes dois tecidos, utilizando colorações especiais e luz polarizada $(26,66,67,68,69)$, porém os resultados não tem sido suficientemente claros para estabelecer parâmetros que permitam separá-los. Provavelmente existe mais de uma linha celular envolvida nestes tumores $(11,44$, $52,70)$. Em vista destas dificuldades tem-se sugerido o nome de "Fibroma Cemento Ossificante" para englobar ambas lesões $(1,34,61,70)$.

É importante o fato, que os cementículos não são exclusivos dos Fibromas Cementificantes, já que, se apresentam em diferentes lesões nos ossos longos, recebendo o nome de "corpos psamomas" $(44,55,70)$, e esta estrutura histológica não influi no compor tamento clínico destas lesões.

\section{MATERIAL E MÉTODO}

Foram revisados os arquivos do Serviço de Anatomia Patológica da Escola Dental e do Centro de Referência de Patologia Oral da Faculdade de Odontologia da Universidade do Chile, e foram selecionados 18 casos de lesões Fibro-ósseas Benignas dos Maxilares, compostos por seis Displasias Fibrosas Monostóticas, seis Fibromas Ossificantes e seis Fibromas Cementificantes.

$\mathrm{Se}$ analisou cada caso em particular, levando em conta suas características clínicas, radiográficas e histológicas, as que tinham que corresponder as descrições da literatura para seu tipo. Foram deixadas de lado todas aquelas que apresentavam alguma dúvida (Tab. 1).

Todas as mostras dos casos selecionados estavam incluidas em parafina. Se obtiveram 120 cortes seriados de 5 micrômetros de espessura cada um deles. Se montaram dois cortes por lâmina, em um total de 60 preparações histológicas por caso. Estas foram agrupadas em seis séries sucessivas e numeradas de 1 a 10.

As colorações foram: Hematoxilina de Harris e Eosina (H/E) (39); Técnica Tricrômica de Van Gieson Ponceau (VG Ponceau) (42); Técnica de ácidos periódicos de Schiff (PAS) para mucopolissacarideos (35) de acordo com o esquema seguinte:

\begin{tabular}{lrrrrrrl}
\hline Série & I & II & III & IV & V & VI & \\
& 1 & 1 & 1 & 1 & 1 & 1 & H/E \\
Número de & 2 & 2 & 2 & 2 & 2 & 2 & VG Ponceau \\
Lâminas & 3 & 3 & 3 & 3 & 3 & 3 & PAS \\
Histológicas & 4 & 4 & 4 & 4 & 4 & 4 & Parafina (reserva) \\
& 5 & 5 & 5 & 5 & 5 & 5 & Parafina (reserva) \\
& - & - & - & - & - & - & Parafina (reserva) \\
& 10 & 10 & 10 & 10 & 10 & 10 & Parafina (reserva)
\end{tabular}

TABELA 1 - Quadro resumido das principais características clínico-radiográficas dos casos empregados neste trabalho.

\begin{tabular}{|c|c|c|c|c|c|}
\hline $\begin{array}{l}\text { N: DEL } \\
\text { CASO }\end{array}$ & $\begin{array}{l}\text { EDAD } \\
\text { (años) }\end{array}$ & SEXO & LOCALIZACION & $\begin{array}{c}\text { ASPECTO } \\
\text { RADIOGRAFICO }\end{array}$ & $\begin{array}{c}\text { DIAGNÓSTICO } \\
\text { HISTOPATOLOGICO }\end{array}$ \\
\hline 1 & 15 & M & Maxila lado izq. & Vidrio esmerilado & Displasia Fibrosa \\
\hline 2 & 19 & $\mathrm{~F}$ & Maxila lado izq. & R.L. con putos RP & Displasia Fibrosa \\
\hline 3 & 12 & $M$ & Maxila lado der. & Moteado & Displasia Fibrosa \\
\hline 4 & 5 & M & Maxila lado der. & RL con loculaciones & Displasia Fbrosa \\
\hline 5 & 15 & M & Maxila lado izq. & $\begin{array}{l}\text { Misto velamiento } \\
\text { de seno }\end{array}$ & Displasia Fibrosa \\
\hline 6 & 17 & M & $\begin{array}{l}\text { Maxila y seno } \\
\text { maxilar lado der. }\end{array}$ & RP lifmites difusos & Displasia Fibrosa \\
\hline 7 & 21 & $\mathbf{F}$ & $\begin{array}{l}\text { Mandibula ángulo } \\
\text { derecho }\end{array}$ & $\begin{array}{l}\mathrm{RL} \text { y RP bordes } \\
\text { corticalizados }\end{array}$ & Fibroma Osificante \\
\hline 8 & 12 & $\mathbf{F}$ & $\begin{array}{l}\text { Mandibula } 1 \text { ra. M. } \\
\text { D. lateral izq. }\end{array}$ & Mixta lifmites netos & Fibroma Osificante \\
\hline 9 & 20 & F & $\begin{array}{l}\text { Mandilbula región } \\
\text { anterior }\end{array}$ & $\begin{array}{l}\text { Radiolúcida limites } \\
\text { netos }\end{array}$ & Fibroma Osificante \\
\hline 10 & 59 & $\mathrm{~F}$ & $\begin{array}{l}\text { Mandibula lateral } \\
\text { derecha }\end{array}$ & $\begin{array}{l}\text { R. Mixto bordes } \\
\text { netos }\end{array}$ & Fibroma Osificante \\
\hline 11 & 57 & $F$ & Maxila derecha & $\begin{array}{l}\text { Rx. ópaca limites } \\
\text { netos }\end{array}$ & Fibroma Osificante \\
\hline 12 & 10 & $F$ & $\begin{array}{l}\text { Mandibula ángulo } \\
\text { izquierdo }\end{array}$ & $\begin{array}{l}\text { RX. Spaca limites } \\
\text { netos }\end{array}$ & Fibroma Osificante \\
\hline 13 & 42 & M & Mandíbula lado izq. & Mixta, limites netos & Fibroma Cementificante \\
\hline 14 & 37 & $\mathrm{~F}$ & Maxila lado izq. & Mixta, limites netos & Fibroma Cementificante \\
\hline 15 & 47 & $\mathrm{~F}$ & Mandlbula lado der. & $\begin{array}{l}\text { Radiolúcida, limites } \\
\text { netos }\end{array}$ & Fibroma Cementificante \\
\hline 16 & 49 & M & Mandlbula lado izq. & $\begin{array}{l}\text { Radiopaca, limites } \\
\text { netos }\end{array}$ & Fibroma Cementificante \\
\hline 17 & 27 & M & Mandlbula lado der. & Mixta, limites netos & Fibroma Cementificante \\
\hline 18 & 17 & $F$ & Mandibula mentón & $\begin{array}{l}\text { Radiolúcida, límites } \\
\text { netos }\end{array}$ & Fibroma Cementificante \\
\hline
\end{tabular}


Entre uma série e outra foram deixados 14 cortes de separação, ou seja, 70 micrômetros, o que permite que as medições realizadas não se repitam. Estes cortes foram montados em lâminas e guardados de reserva. Os cortes foram observados em um microscópio binocular Leitz Wetzlar SM-LUX dotado de uma ocular quadriculada (Leitz Wetzlar) de 900 micrômetros por lado.

Todas as lâminas foram colocadas na platina graduada do microscópio sempre da mesma forma, ou seja, com sua identificação a esquerda do operador. Se tomou um ponto de referência no tecido a ser examinado, e se registrou as coordenadas da platina. Deste modo, foi possível regressar com exatidão à área estudada, que foi dada pelo quadriculado da objetiva que se utilizou. As medições se realizaram em três campos contiguos a partir do ponto de referência estabelecido, transladando a lâmina em sentido vertical ou horizontal, de acordo com a posição relativa da mostra.

Se estudou as mostras tissulares tomando em consideração o tecido conjuntivo fibroso e o tecido mineralizado.

\section{Estudo das variáveis do tecido conjuntivo fibroblástico}

Nos cortes corados com Hematoxilina e Eosina e utilizando um aumento de 500X foram estudadas as seguintes variáveis:

1. Celularidade do tecido conjuntivo:

Se contou todas as células que estavam incluidas no campo quadriculado da ocular. As que se encontravam no limite de observação foram incluidas somente as que tinham mais da metade dentro da área.

2. Número de figuras de mitose:

Se utilizou o mesmo procedimento anterior.

3. Pigmento de Hemossiderina:

Se contou todos os campos da área quadriculada, dada pela ocular, onde se observou a presença deste pigmento.

Nos cortes corados de acordo com a técnica de Van Gieson Ponceau, se quantific ou o número de fibras colágenas, com a ajuda de fil- tros polarizadores. Se contou os campos dados pela ocular graduada onde se observava a presença de colágeno, que toma um aspecto briIhante com a polarização. Foi usado em aumento de $500 X$.

Nos cor tes submetidos a reação de PAS, se quantificou o número de vasos sangǘneos registrando todos aqueles que se apresentavam na área determinada, usando um aumento de $125 X$.

\section{Variáveis do tecido mineralizado}

Os componentes do tecido mineralizado, foram quantificados considerando, as células próprias do tecido mineralizado, a área de matriz orgânica depositada em suas duas formas, além da morfologia das mesmas trabéculas.

1. Células: Neste trabalho se definiu as células próprias do tecido mineralizado da seguinte forma: (Fig. 1)

Blastos: células mononucleadas formadoras de matriz orgânica e que se encontram aderidas a ela. Clastos: células multinucleadas que apresentam funções de reabsorção da matriz orgânica mineralizada.

Citos: células incluídas no interior da matriz orgânica.

Estes elementos foram quantificados, utilizando-se um aumento de 500X nas preparações coradas com $H / E$. Se contabilizou todas aquelas que se encontravam no campo quadriculado.

\section{Matriz orgânica:}

Terminada a contagem celular, sem mover a preparação se trocou o aumento para 125X. Mediante o auxílio de uma câmara clara Leitz, se transferiu a imagem histológica a um desenho e neste se fez um gráfico do perfil das trabéculas observadas neste campo. Se diferenciou o perfil da matriz orgânica mineralizada da não mineralizada utilizando cores diferentes.

Se mediu a área total da matriz orgânica depositada em suas duas formas, sobrepondo-se uma transparência quadriculada, cada quadrado tinha $2 \mathrm{~mm}^{2}$ de superficie, sobre o desenho que tinha um aumento final de 139,13X. Se contou o total de quadrados que cabiam no interior dos perfis desenhados. Se eliminou aqueles que se apresentavam nos limites do tecido que estavam ocupados em uma proporção menor que $50 \%$ de sua superfície.

\section{Morfologia das trabéculas:}

Se definiu as trabéculas de tecido mineralizado de acordo com o seguinte esquema:

- Trabéculas Tipo 1 (cementículos): de perfis redondos ou com dimensões aproximadamente iguais (largura não mais que 1,5 vezes o comprimento). (Fig. 2).

- Trabéculas Tipo 2 (trabéculas retangulares): aquelas em que uma dimensão era maior que a outra (a largura sobrepassa o comprimento entre 1,5 a 3 vezes). (Fig. 3).

- Trabéculas Tipo 3 ("caracteres chineses"): formações em que uma das dimensões era maior que a outra (largura era mais de 3 vezes o comprimento) e/ou que apresentavam uma troca de direção em sua longitude. (Fig. 4).

O valor total da área de matriz orgânica se obteve através da soma do valor obtido para a matriz orgânica não mineralizada e o da matriz orgânica mineralizada. Esta cifra nos deu também a área total de tecido mole pela diferença entre a área total de matriz orgânica e a área da transparência quadriculada utilizada para medição.

\section{Correlação de Variáveis e Obtenção de Índices}

Os valores obtidos nas medições realizadas foram utilizados para estabelecer os seguintes indices:

- Indice de Colagenização: obtido pela divisão da quantidade de células desta mesma área, pelo colágeno.

- Indice de Fragilidade Capilar: foi tomado o produto da divisão das áreas hemorrágicas pelo número de vasos sangüĺneos do campo.

- Indice de Diferenciação em Blastos: considerando-se o valor da divisão do número de blastos pela celularidade de cada campo microscópico.

- Índice de Produção de Matriz Orgânica: resultado da divisão da área 


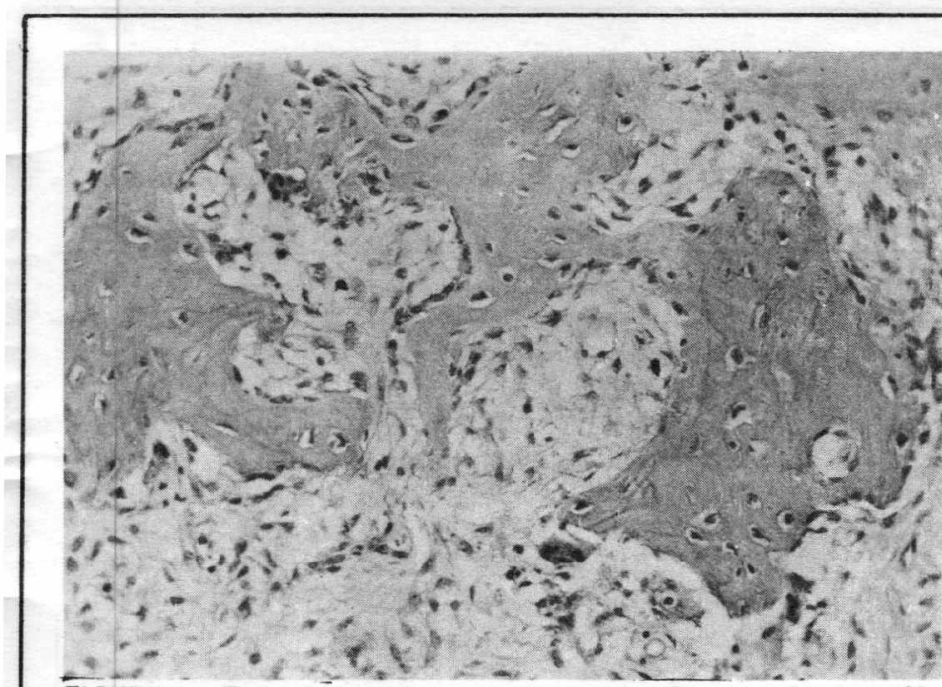

FIGURA 1 - Fotomicrografla onde se mostra Blastos; Clastos; Cltos. (FIbroma Oesificante/H/E/312,5X).

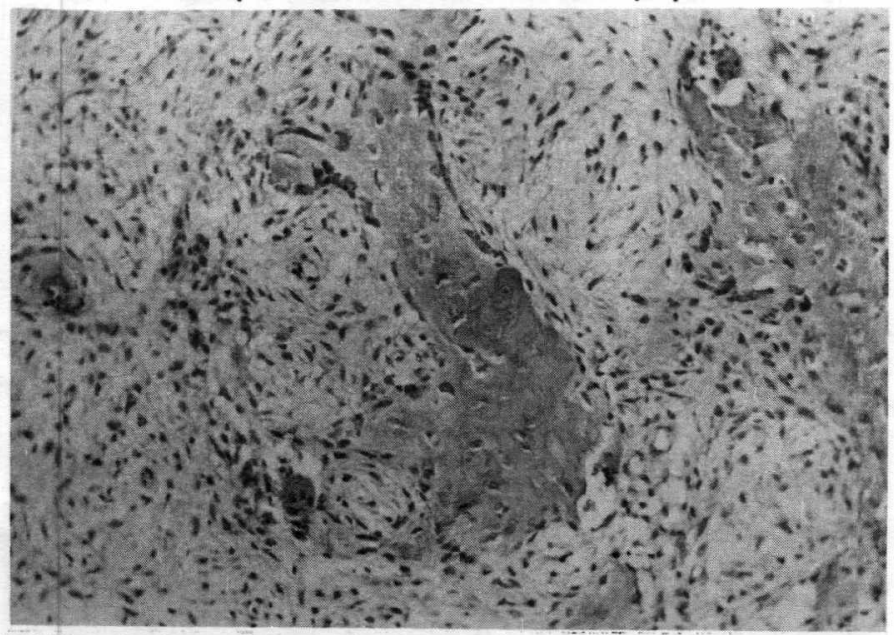

FIGURA 3 - Fotomicrografia de trabéculas retangulares (Fibroma Ossific ante/H/E/321,5X).

de matriz orgânica não mineralizada pelo número de blastos nestes campos.

- Índice de Mineralização da Matriz Orgânica: obtido pela divisäo da área de matriz orgânica mineralizada pelo número de blastos.

- Indice de Atividade Total de Blastos: tomado o produto da divisão da área total de matriz orgânica depositada em suas duas formas pelo número de blastos contados nestes campos.

\section{RESULTADOS}

$\mathrm{Na}$ Tabela 2 se apresenta um quadro resumido de todos os valores obtidos neste trabalho, considerando, tanto o tecido conjuntivo fibroso e o tecido mineralizado como os indices que se determinou. Os dados particulares para cada uma destas variáveis estão indicados na Tabela,

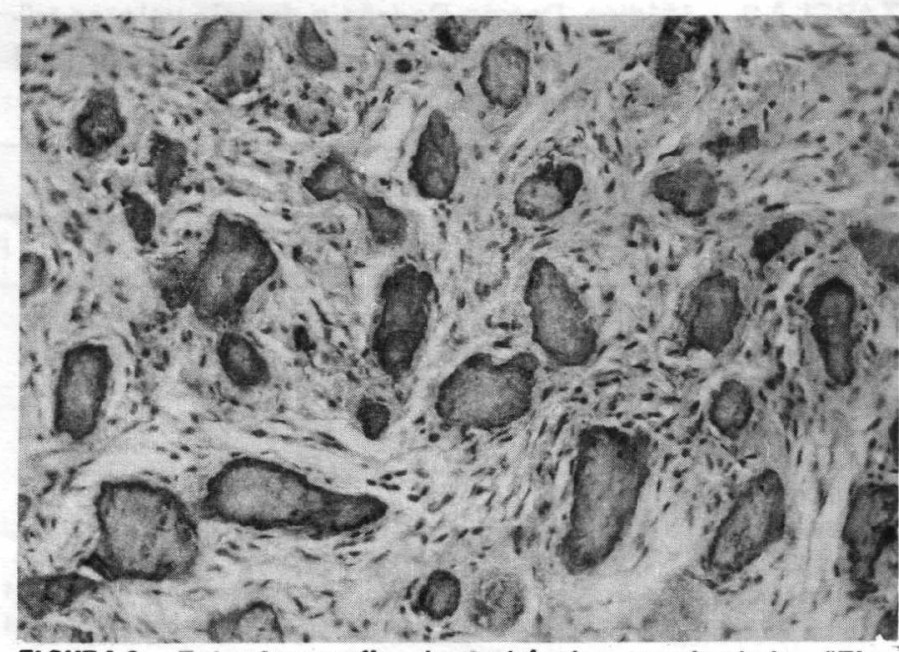

FICURA 2 - Fotomicrografla de trabłculas arredondadas "Tipo Cementiculos". (Fibroma Cementificante/H/E/312,5X).

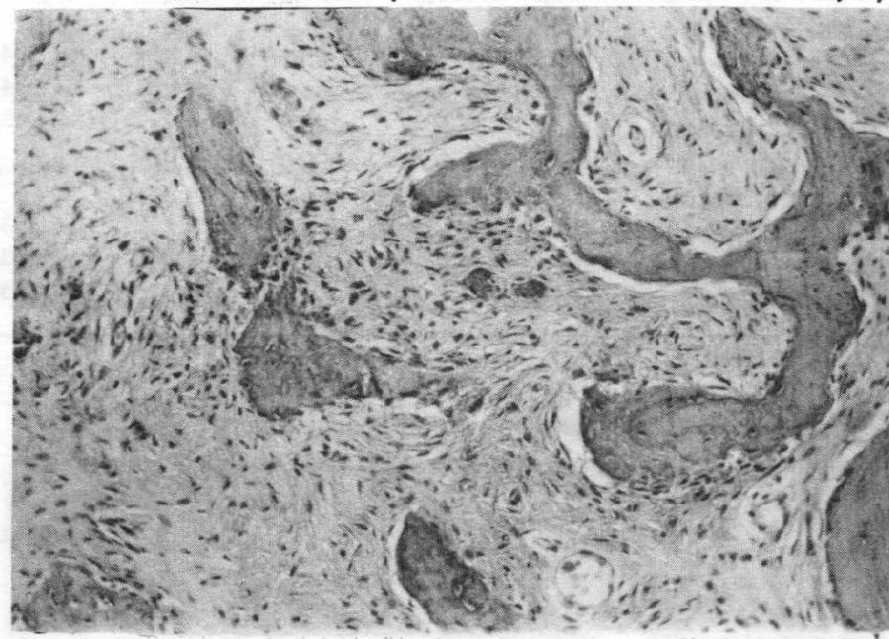

FIGURA 4 - Fotomicrografia de trabóculas alargadas ou em "caracteres chineses". (Displasia Fibrosa/H/E/312,5X). a sigla F.C.é Fibroma Cementificante, F.O. é Fibroma Ossificante e D.F. é Displasia Fibrosa.

\section{DISCUSSÃo}

Foram analisados os resultados obtidos considerando todas as variáveis propostas para o estudo da Displasia Monostótica, do Fibroma Ossificante e Fibroma Cementificante. Logo, discutiremos quais delas são mais apropriadas para a diferenciação histológica.

\section{Características do Tecido Conjuntivo Fibroso}

O estudo da celularidade do tecido conjuntivo fibroso das três lesões, demonstrou que os valores médios obtidos apresentam diferenças significativas entre si. Na literatura só é mencionada de forma muito geral, a quantidade de células que compõem o tecido mole destas lesões, porém sem estabelecer padrões objetivos $(11,18,19,26,36$, $50,56,70,71)$. Os resul tados obtidos neste estudo, Tabela 2, são significativos se forem comparadas as médias analisando-se que o Fibroma Cementificante apresentou 0 valor mais alto $(238,8)$, seguido do Fibroma Ossificante $(207,3)$ e a Displasia Fibrosa $(175,4)$, Figuras 6, 7 e 8.

Aparentemente este seria um parâmetro que se poderia considerar histologicamente para a discriminação entre estas lesões, porém se observando os valores mínimos, indicados na mesma Tabela, se pode ver que entre a Displasia Fibrosa e o Fibroma Ossificante quase não há diferença e o Fibroma Cementificante apresenta 0 valor mais baixo $(55,0)$, em contraste com o valor máximo que é o mais alto do grupo de lesões $(537,0)$. Este fato indica que a celu- 
TABELA 2- Médias, Desvio Padrão e demais valores minimos e máximos obtidos em cada Variável por Diagnóstico.

\begin{tabular}{|c|c|c|c|c|c|c|c|c|c|c|c|c|}
\hline \multirow[t]{2}{*}{ VARIABLE } & \multicolumn{8}{|c|}{$X^{*}(+D S)^{* *}$} & \multicolumn{2}{|c|}{ RANGO*** } & & \\
\hline & \multicolumn{2}{|c|}{ D F } & \multicolumn{2}{|c|}{ Fo } & \multicolumn{2}{|c|}{$\mathrm{FC}$} & \multicolumn{2}{|c|}{$D F$} & \multicolumn{2}{|c|}{ Fo } & \multicolumn{2}{|c|}{ F C } \\
\hline Celularidad & 175,4 & 61,7 & 207,3 & 98,4 & 238,8 & 114,1 & 85,0 & 364,0 & 78,0 & 447,0 & 55,0 & 533,0 \\
\hline Mitosis & 0,0 & 0,0 & $9 \mathrm{E}^{-3}$ & 0,09 & 0,0 & 0,0 & 0,0 & 0,0 & 0,0 & 1,0 & 0,0 & 0,0 \\
\hline Hemorragia & 02 & 0,6 & 0,1 & 0,4 & 0,2 & 0,5 & 0,0 & 3,0 & 0,0 & 2,0 & 0,0 & 3,0 \\
\hline Colageno & 89 & 14,0 & 91,1 & 13,0 & 98,8 & 2,4 & 44,0 & 100,0 & 25,0 & 100,0 & 86,0 & 100,0 \\
\hline Vasos & 14,9 & 7,5 & 24,5 & 12,4 & 17,7 & 7,9 & 1,0 & 41,0 & 8,0 & 59,0 & 5,0 & 48,0 \\
\hline Blastos & 18,0 & 8,3 & 24,2 & 13,1 & 20,0 & 13,3 & 0,0 & 36,0 & 0,0 & 56,0 & 0,0 & 52,0 \\
\hline Clastos & 0,3 & 0,6 & 1,3 & 1,4 & 0,1 & 0,7 & 0,0 & 3,0 & 0,0 & 8,0 & 0,0 & 8,0 \\
\hline Citos & 16,6 & 10,4 & 18,3 & 12,5 & 5,6 & 6,6 & 0,0 & 49,0 & 0,0 & 60,0 & 0,0 & 48,0 \\
\hline Matriz Orgânica & $5,7 \mathrm{E}^{4}$ & $5,2 \mathrm{E}^{4}$ & $4,7 \mathrm{E}^{4}$ & $3,5 \mathrm{E}^{4}$ & $10,1 \mathrm{E}^{4}$ & $18,7 E^{4}$ & 0,0 & $21,5 \mathrm{E}^{4}$ & 0,0 & $18,2 E^{4}$ & 0,0 & $65,1 E^{4}$ \\
\hline Matriz Mineraliz. & $13,9 E^{4}$ & $9,7 E^{4}$ & $15,4 E^{4}$ & $12,2 \mathrm{E}^{4}$ & $10,9 E^{4}$ & $9,4 \mathrm{E}^{4}$ & 0,0 & $48,3 E^{4}$ & $3,9 \mathrm{E}^{3}$ & $59,2 \mathrm{E}^{4}$ & $1,6 \mathrm{E}^{3}$ & $47,4 E^{4}$ \\
\hline Prop.Trab. Tipo 1 & 13,0 & 16,0 & 25,4 & 18,4 & 59,9 & 24,6 & 0,0 & 80,0 & 0,0 & 92,3 & 0,0 & 100,0 \\
\hline Prop. Trab. Tipo 2 & 26,7 & 19,8 & 71,0 & 18,6 & 37,4 & 24,4 & 0,0 & 100,0 & 7,6 & 100,0 & 0,0 & 100,0 \\
\hline Prop. Trab. Tipo 3 & 60,1 & 24,5 & 3,4 & 7,5 & 2,5 & 6,7 & 0,0 & 100,0 & 0,0 & 42,8 & 0,0 & 44,4 \\
\hline Matriz Total & $19,7 \mathrm{E}^{4}$ & $8,6 \mathrm{E}^{4}$ & $20,1 E^{4}$ & $11,3 \mathrm{E}^{4}$ & $21,2 E^{4}$ & $18,1 E^{4}$ & $3,3 E^{4}$ & $5,5 \mathrm{E}^{5}$ & $2,0 E^{4}$ & $6,3 E^{5}$ & $0,4 \mathrm{E}^{4}$ & $6,6 E^{5}$ \\
\hline Área Tej. Blando & $54,6 \mathrm{E}^{4}$ & $8,6 E^{4}$ & $54,2 \mathrm{E}^{4}$ & $11,3 \mathrm{E}^{4}$ & $53,2 E^{4}$ & $18,1 E^{4}$ & $18,8 \mathrm{E}^{4}$ & $7,1 \mathrm{E}^{5}$ & $11,0 \mathrm{E}^{4}$ & $7,2 \mathrm{E}^{5}$ & $8,1 E^{4}$ & $7,3 E^{5}$ \\
\hline Ind. Colagenizacion & 0,5 & 0,2 & 0,5 & 0,2 & 0,5 & 0,3 & 0,1 & 1,1 & 0,07 & 1,1 & 0,1 & 1,8 \\
\hline Ind. Frag. Capilar & 0,1 & 0,2 & 02 & 0,05 & 0,05 & 0,1 & 0,0 & 1,6 & 0,0 & 0,3 & 0,0 & 0,8 \\
\hline I. Diferen. Blastos & 0,10 & 0,05 & 0,12 & 0,07 & 0,08 & 0,04 & 0,0 & 0,3 & 0,0 & 0,3 & 0,0 & 0,2 \\
\hline I. Prod. M. Organic. & $9,3 \mathrm{E}^{2}$ & $9,8 E^{2}$ & $5,7 \mathrm{E}^{3}$ & $7,3 E^{2}$ & $12,4 E^{3}$ & $23,3 E^{2}$ & 0,0 & $5,5 \mathrm{E}^{3}$ & 0,0 & $6,0 E^{3}$ & 0,0 & $13,5 E^{3}$ \\
\hline I. Miner. M. Organic. & $2,3 E^{3}$ & $1,9 E^{3}$ & $2,7 E^{3}$ & $3,6 \mathrm{E}^{3}$ & $1,9 \mathrm{E}^{3}$ & $1,9 E^{3}$ & 0,0 & $9,6 E^{3}$ & 65,4 & $16,8 \mathrm{E}^{3}$ & 68,8 & $10,6 \mathrm{E}^{3}$ \\
\hline I. Activ. Blastos & $3,2 E^{3}$ & $1,9 E^{3}$ & $3,3 E^{3}$ & $3,7 \mathrm{E}^{3}$ & $3,1 E^{3}$ & $2,9 E^{3}$ & 523,8 & $1,1 E^{4}$ & 502,8 & $1,7 \mathrm{E}^{4}$ & 292,7 & $2,3 E^{4}$ \\
\hline
\end{tabular}

${ }^{*} \mathrm{X}=$ Promedio

${ }^{* *}(+\mathrm{DS})=$ Desviacion Standard

"*"Rango = Valores minimos y maximos encontrados

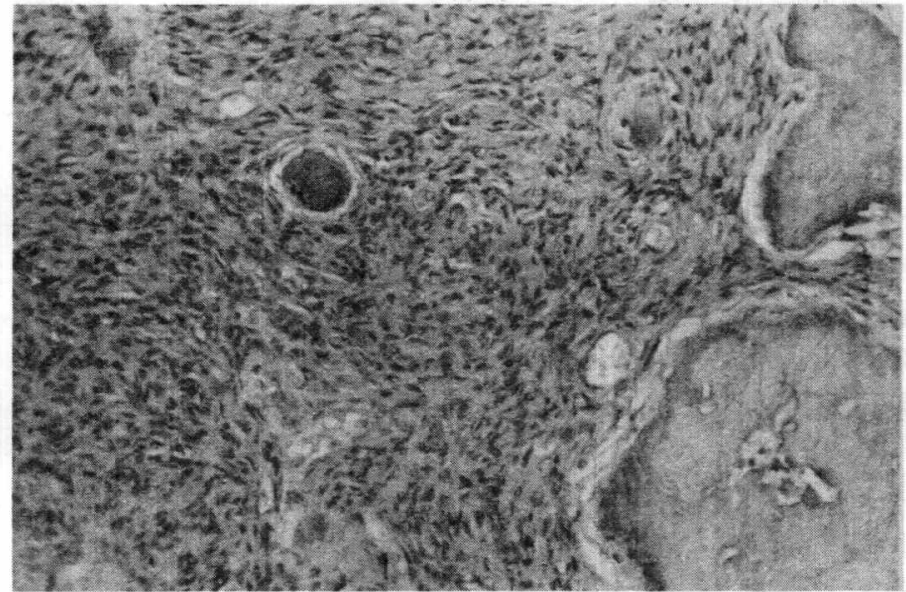

FIGURA 5 - Fotomicrografla que llustra a grande celularidade e presença marcante de fibras colágenas em Fibroma Cementificante (H/E/312,5X).

laridade da lesão para casos particulares não pode ser empregada por si só para diagnosticar uma lesão ou outra, apesar de existi uma tendência em favor do Fibroma Cementificante em relação ao maior número de células.

A idéia da maioria dos autores $(1,6,11,18,19,26,28,29,40,41$, $50,55,56,70,71,72)$ de que estas lesões são de crescimento lento se viu confirmada pelo achado de uma só figura de mitose nas 324 áreas estudadas. Esta .correspondeu a um

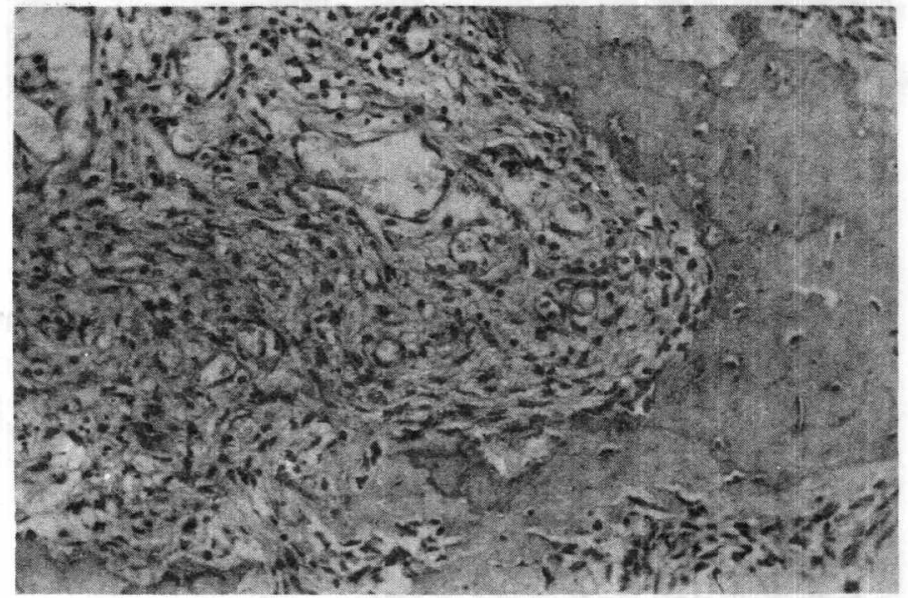

FIGURA 6 - Fotoml crografla de tecldo mole de um Fibroma Ossificante, notar a marcada vascularização e a presença de grande quantidade de células e flbras colágenas. Há componente Inflamatórlo sobreposto (H/E/312,5X).

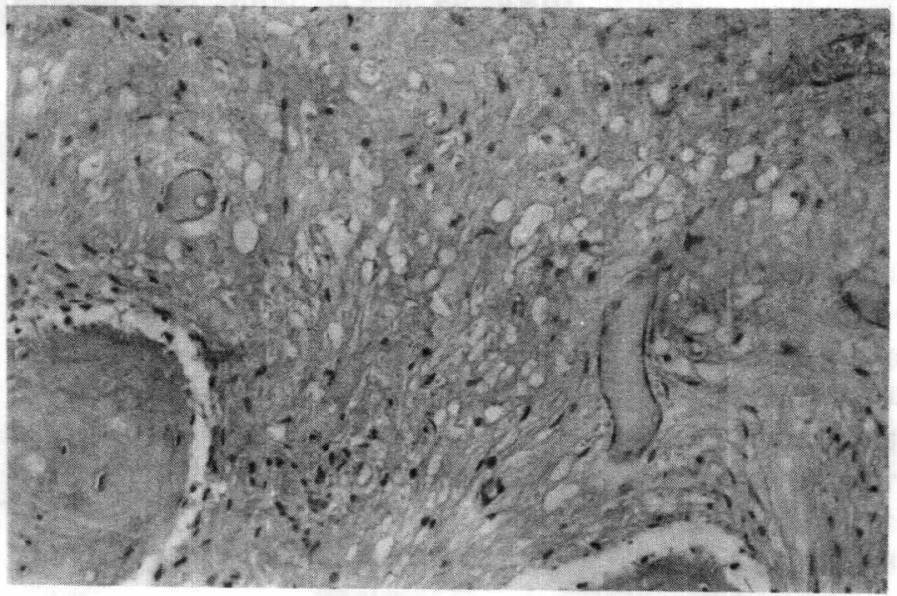

FIGURA 7 - Fotomicrografla de uma área fibroblástica. Caso de Displasia FIbrosa, é possivel notar a menor celularidade colagenização (H/E/312,5X). 


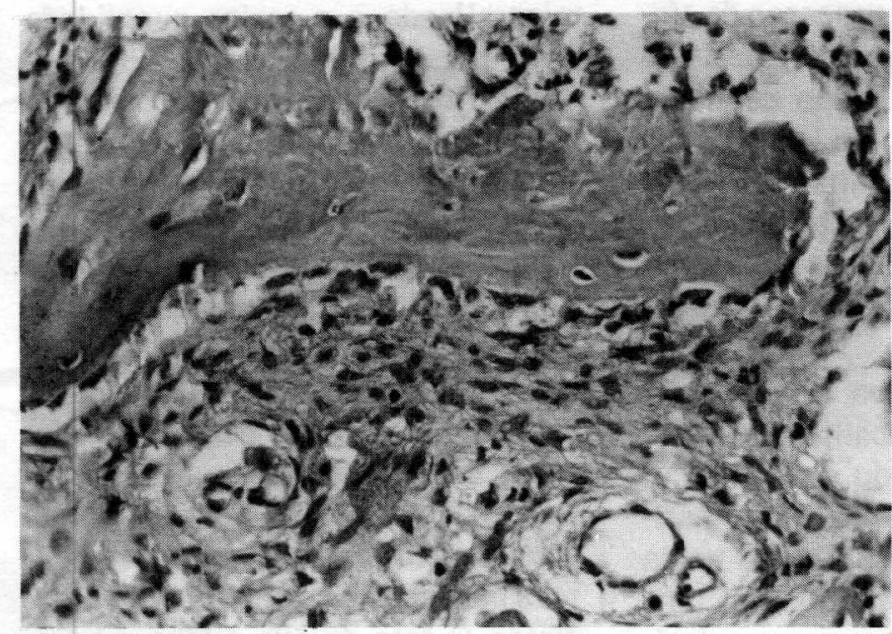

FIGURA 8 - Fotomicrografia onde se Indica a presença de atividade osteoblástica em trabéculas de Displasia Fibrosa (H/E/500X).

FIGURA 9 - Fotomicrografia de um Fibroma Cementificante, é importante notar a diferença entre a trabécula da esquerda (cemento) com poucos citos $e$ uma grande área de matriz orgânica não mineralizada. Comparar com a trabécula óssea da direlta (H/E/312,5X).

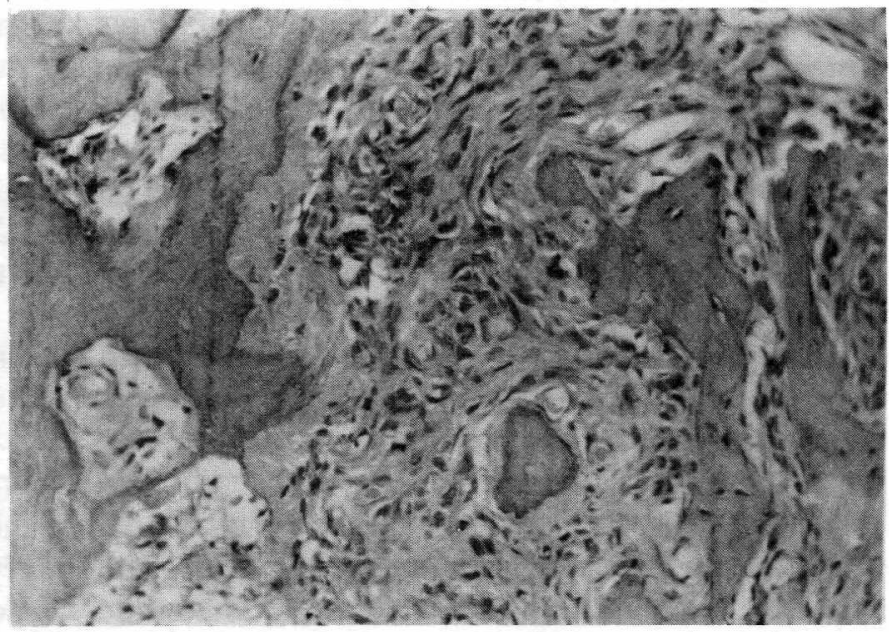

Fibroma Ossificante. Nesta lesão e em zonas não compreendidas no estudo se encontrou algumas escassas células em divisão, o que, aparentemente indicaria que são lesões com uma proliferação um pouco mais ativa.

Não se pode demonstrar a afirmação de Lichtenstein (37), que as áreas hemorrágicas seriam predominantes na Displasia Fibrosa. A média encontrada para esta lesão é a mais alta do grupo, porém não apresenta diferenças significativas, Tabela 2 , inclusive seu valor $\dot{\theta}$ semelhante ao encontrado para o Fibroma Cementificante, tanto a média como o valor máximo e mínimo. Indubi tavelmente, este parâmetro não pode ser utilizado como antecedente para o diagnóstico diferencial destas três lesões.

O Fibroma Ossificante apresentou a maior vascularização, sendo esta uma diferença significativa em relaçăo as outras lesōes. Entre a Displasia Fibrosa e o Fibroma Cementificante não se observou a exis- pode comprovar.

Por outro lado, o índice de fragilidade capilar mostrou diferenças significativas entre Displasia Fibrosa, Fibroma Ossificante e Cementificante. É interessante ressaltar que o índice de fragilidade capilar mais alto foi encontrado nos casos de Displasia Fibrosa. A aparente contradição entre os resultados de "Hemorragia", Tabela 2, e índice de fragilidade capilar se explica devido a que correlaciona a quantidade de vasos por campo com a quantidade de áreas hemorrágicas, e possivelmente esta marcada relação vaso-hemorragia tenha induzido diversos autores a pensar que a Displasia Fibrosa seria uma lesão de vascularização e hemorragia proeminentes $(18,37,67)$.

O Fibroma Cementificante apresentou a maior quantidade de fibras colágenas, sendo esta uma diferença significativa em relação ao Fibroma Ossificante e Displasia Fibrosa. Se forem comparados os valores mínimos e máximos obtidos para esta lesão, vê-se que são muito homogêneos, o que determina seu caráter fibroso e colabora com a idéia proposta por Hamner et al (26), que o Fibroma Cementificante se origina no periodonto. Freeman (22), afirma que o ligamento periodontal apresenta como característica sua riqueza em fibras colágenas. Também se tem assegurado ao Fibroma Ossificante uma origem periodontal, porém nossos resultados demonstram que a quantidade de fibras colágenas é significativamente menor e que o valor mínimo encontrado está muito abaixo da cifra obtida para o Fibroma Cementificante, o que, estabeleceria que as células desta lesão teriam uma diferenciação predominante de outro tipo funcional. De acordo com os resultados expressos na Tabela 2, a diferenciação tenderia à formação de tecido ósseo. Este achado tende a confirmar que no Fibroma Ossificante a diferenciação das células que o compōem é distinta do Fibroma Cementificante.

Não se pode descartar sua origem periodontal, já que Bordin et al (9) demonstraram subtipos de fibroblastos com orientações funcionais distintas. 
O índice de colagenização estabelecido, que relaciona número de células no tecido conjuntivo com o número de fibras colágenas, demonstra que não existem diferenças significativas entre as três lesões estudadas. Isto indica que os fibroblastos têm a mesma capacidade formadora de colágeno, independentemente de se encontrarem no Fibroma Cementificante, Fibroma Ossificante e Displasia Fibrosa.

\section{Características do Tecido Mineralizado}

O Fibroma Ossificante apresentou o valor mais alto para as células formadoras de matriz orgânica, definidas como blastos. Este mostra uma diferença significativa com a Displasia Fibrosa e o Fibroma Cementificante. Entre estas duas últimas lesões, a Displasia Fibrosa é a que tem o número mais baixo de blastos, superada por uma escassa margem pelo Fibroma Cementificante. Se tem postulado que a Displasia Fibrosa não apresenta osteoblastos ativos, Hamner et al (26), que consideram estes casos como outra lesão. Waldron et al (67), e Eversole et al (18), sustentam que na periferia das trabéculas da Displasia Fibrosa se enc on tram oste oblastos ativos. Nossos resultados concordam com esta última afirmação. As três lesões apresentam células blásticas aderidas as trabéculas do tecido mineralizado. Se observarmos na Tabela 2, os dados de matriz orgânica não mineralizada, osteóide ou cementóide, é possivel ver que todos os casos apresentam este tipo de substância, indicando que os blastos neles encontrados são ativos.

No caso particular de Displasia Fibrosa, esta ocupa o segundo lugar sobre o Fibroma Ossificante. Esțe achado, junto com os dados encontrados para as células formadoras de matriz, estabelecem que esta lesão apresenta osteoblastos ativos. Alguns autores propõem que as células encontradas nas trabéculas de ossos da Displasia Fibrosa seriam "Fibroblastos Displásicos" $(7,18,25$, $26,41,50$ ).

Segundo Ten Cate (63) a nivel estrutural não existem diferenças entre um fibroblasto e um osteoblas- to, quando estão em processo de síntese proteica, portanto, a única forma de estabelecer o tipo celular é por seus produtos. Se uma célula mesenquimática deposita matriz óssea, esta é um osteoblasto, ainda que esteja produzindo osso irregular, que é característica na Displasia Fibrosa. (Fig. 9).

Considerando que nesta lesão temos primeiro a substituição de tecido ósseo por tecido conjuntivo, 0 qual, paulatinamente vai sendo ossificado, é possível propor que nesta segunda fase se produziria uma orientação das células mesenquimáticas não diferenciadas em células formadoras de matriz óssea, fenômeno que também é possível encontrar normalmente na reparação de osso (56), sem que isto signifique que os fibroblastos sejam responsáveis pelo osteóide encontrado.

O Fibroma Ossificante apresentou a maior atividade de reabsorção, expressa pelo número de clastos que se encontrou aderidos as trabéculas mineralizadas. A Displasia Fibrosa e - Fibroma Cementificante demonstraram uma diferença significativa com esta lesão, porém ambos valores obtidos foram muito próximos.

Se forem comparados os dados obtidos no Fibroma Ossificante para o número de blastos e de clastos, se pode observar claramente, que em termos proporcionais esta lesão apresenta a maior atividade de aposição e reabsorção de matriz mineralizada.

O Fibroma Cementificante apresentou a média mais baixa de clastos, o que pareceria confirmar que a matriz mineralizada produzida por esta lesão é efetivamente cemento, já que, neste tecido o fenómeno de reabsorção apresenta um ritmo mais baixo que 0 tecido ósseo $(22,50$, 56).

Outro achado que parece confirmar esta afirmação é que o número de citos, células incluídas na matriz orgânica, foi significativamente menor que 0 do Fibroma Ossificante e Displasia Fibrosa, que são lesões nas quais se pode encontrar tecido ósseo, maduro ou imaturo.

$\mathrm{Na}$ Tabela 2 é possivel observar que o Fibroma Cementificante apresenta a menor quantidade de matriz mineralizada e a maior quantidade de matriz não mineralizada (Fig. 10).

Por outro lado, no Fibroma Ossificante, se produz a situação inversa. Estes valores apresentam uma diferença significativa nas medições realizadas. Os valores para Displasia Fibrosa se mantém entre os de outras lesões, não estabelecendo-se uma diferença significativa entre elas. Estes achados permitem colaborar com a proposição já apresentada, de que o Fibroma Ossificante e o Cementificante apresentam algumas caracteristicas histológicas distintas. $\mathrm{O}$ fato de que o Fibroma $\mathrm{Ce}$ mentificante seja a lesão de menor quantidade de matriz não mineralizada permite supor que o fenômeno de depósito de sais seja mais lento que nas outras duas alterações estudadas, já que, a área total de matriz orgânica depositada em suas duas formas, Tabela 2, é praticamente igual, com um valor em torno de 2 milhões de micrômetros quadrados por campo medido.

O tecido mineralizado adota a forma de trabéculas, as quais, podem apresentar morfologias diferentes. Esta característica tem sido utilizada para efetuar o diagnóstico diferencial entre as lesões que são analisadas neste trabalho. De acordo com estes critérios se propõe três variedades de trabéculas que correspondem as descritas para cada lesão em particular.

A proporção de trabéculas Tipo I, "cementiculos", foi mais alta nos casos de Fibromas Cementificantes, com uma diferença significativa em Fibroma Ossificante e Displasia Fibrosa. Este achado confirma a descrição da maioria dos autores que destacam que as trabéculas desta lesão tem aspecto de "cementículos", ou de cemento secundário $(11,40$, $44,50,56)$. Estruturas semelhantes a estas podem apresentar-se em ossos longos (44, 55), sem nenhuma conexão com o periodonto ou cemento.

As trabéculas retangulares, Tipo II, predominaram no Fibroma Ossificante com diferenças significativas entre as três lesões. Esta característica apóia as afirmaçōes encontradas na li tera tura, de que as trabéculas do Fibroma Ossificante são se- 


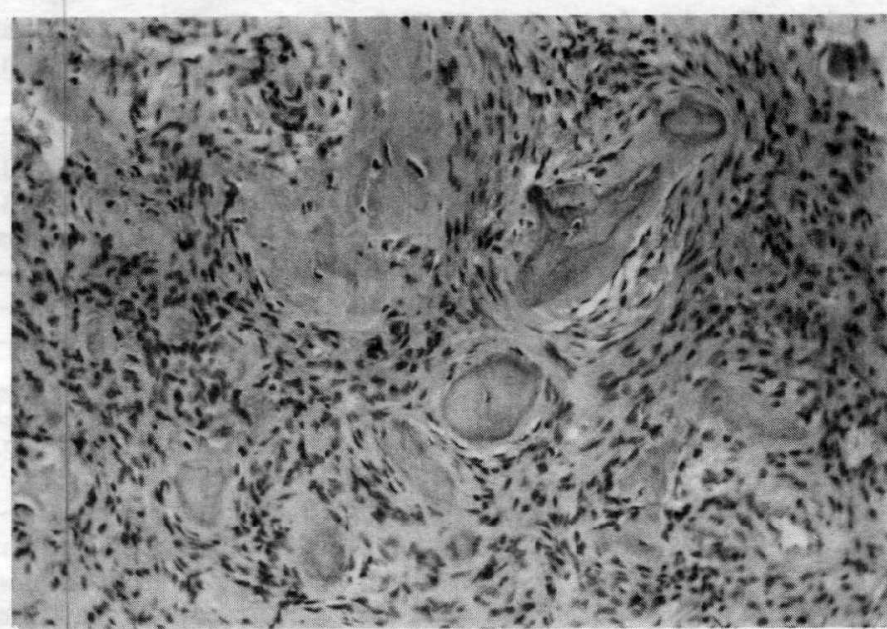

FIGURA 10 - Fotomicrografia que most ra área típica de Fibroma Cementificante em um caso de Fibroma Ossificante (H/E/312,5X).

melhantes às de osso esponjoso.

Também se pode comprovar que na Displasia Fibrosa as trabéculas adotam uma forma muito especial de "caracteres chineses", que foram denominados neste trabalho como de Tipo III. Esta descrição foi feita por numerosos autores $(18,24,28$, $29,36,37,44,50,56$ ).

Os resultados obtidos confirmam as descrições clássicas que aparecem na literatura referentes a Displasia Fibrosa, Fibroma Ossificante e Fibroma Cementificante. É importante ressaltar um achado que não havia sido informado nem quantificado previamente. Se é certo que - tipo de trabéculas característico de uma determinada lesão foi o mais predominante, também é certo que em todas as lesões se pode estabelecer a presença de todas as variedades de formas. Este fato pode determinar erros no diagnóstico, quando a amostra é muito pequena ou por azar se pode cair em uma zona que não seja característica da lesão que se está investigando. Outro aspecto interessante, é o fator subjetivo que depende do observador, já que, em campos em que se apresentam dois ou os três tipos de trabéculas em forma simultânea, este pode deixar-se impressionar por um em particular e não reconhecer os outros $(15,20,32,33,59)$. Também esta situação explica a posição de alguns autores que tem proposto nomes distintos a lesões que apresentam aspectos histológicos variáveis $(34$, $44,47,70)$, Figs. 11 e 12 , tais como Fibroma Cemento-Ossificante (61,

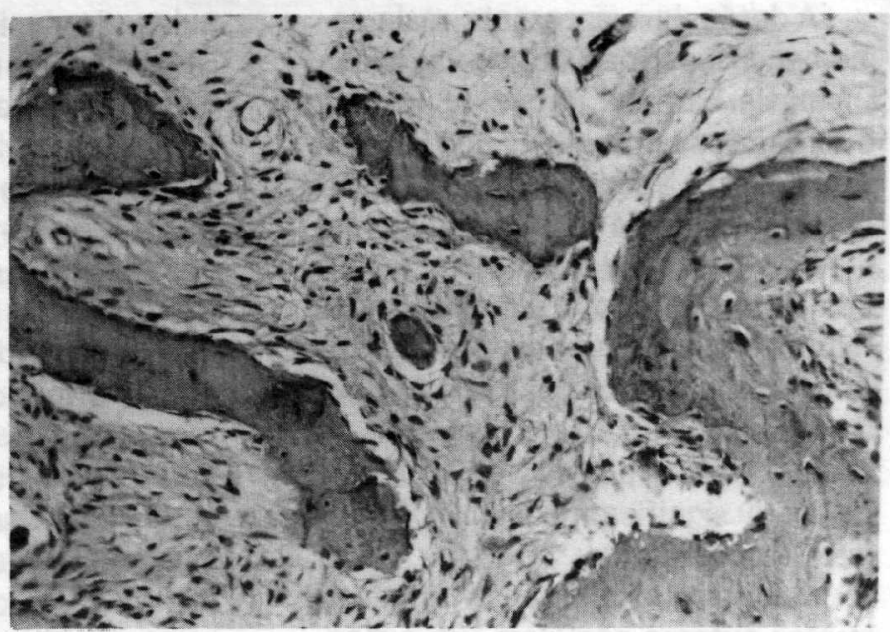

FIGURA 11 - Fotomicrografia de um caso de Displasia FIbrosa onde se vê a presença de massa esférica calcificada semelhante a cementiculos (H/E/312,5X).
70), ou lesão Fibro-óssea híbrida (8). Estas proposiçōes que buscam um termo único que englobe o Fibroma Cementificante com o Fibroma Ossificante, poderiam ter um valor clínico-radiográfico, porém do ponto de vista da histologia, não parece concordante com os achados deste trabalho, que demonstram diferenças entre as células fibroblásticas que compõem o Fibroma Ossificante e Cementificante.

A investigação nesta área deve seguir tentando buscar a confirmação ou não da origem comum de ambas lesões.

\section{Características Histológicas Diferenciais}

O obje tivo principal deste estudo é estabelecer parâmetros objetivos para poder diferenciar histologicamente a Displasia Fibrosa, o Fibroma Ossificante e o Fibroma Cementificante.

As variáveis estudadas que estão expressas na Tabela 2, cobrem os aspectos histológicos mais importantes destas lesões. Os valores obtidos para elas, em alguns casos demonstraram diferenças significativas entre as três lesōes, entre duas delas com a outra ou nenhuma diferença.

Algumas destas se pode usar para a discriminação entre uma $\theta$ outra, já que são facilmente pesquisáveis e confiáveis. Por outro lado, outras, ainda que estatisticamente significativas, em um caso particular é difícil aplicá-las devido a se basea- rem em valores médios e a lesão em questão poderia estar em um dos valores extremos que se sobrepõe com o de outra lesão. Uma das variáveis mais confiáveis é a forma das trabéculas, as quais, em amostras bem obtidas e amplas permitem determinar histologicamente o tipo de lesão.

As trabéculas com forma de "caracteres chineses" são próprias da Displasia Fibrosa, os "cementículos" do Fibroma Cementificante e as trabéculas retangulares, semelhantes às de osso esponjoso, do Fibroma Ossificante.

Entre as variáveis que permitem separar, pelo menos um tipo lesional dos outros dois, se pode indicar a quantidade de células formadoras de matriz, blastos e a de células de reabsorção, as quais estavam em maior quantidade no Fibroma Ossificante. É importante destacar, que apesar de alguns autores negarem a presença de osteoblastos na Displasia Fibrosa, como se mencionou anteriormente, estes podem ser vistos em algumas trabéculas.

Outra das variáveis interessantes, que permite identificar o Fibroma Cementificante, é a relacionada com a formação de matriz não mineralizada, a qual é significativamente mais abundante que nas outras lesões estudadas. Assim mesmo, também no Fibroma Cementificante encontramos escassa quantidade de citos, células incluídas nas lacunas da matriz mineralizada, em relação com - Fibroma Ossificante e a Displasia Fibrosa (ver Fig. 10). 
A lesão que apresenta mais semelhanças com as outras duas é a Displasia Fibrosa, já que, só mostra diferenças significativas nos valores obtidos para a formação de trabéculas, o indice de diferenciação em blastos e a celularidade do tecido conjuntivo fibroso. $O$ indice de fragilidade capilar, que segundo Lichtenstein (37) se traduziria em abundante hemorragia, era superior as outras lesões, porém não estatisticamente significativo com o Fibroma Cementificante.

Como se propôs anteriormente, muitos autores postulam que o diagnóstico correto destas lesões se deve efetuar correlacionando a clínica, radiologia e a histologia $(11,15,18$, $29,44,55,56,70)$.

Desde o ponto de vista histológico, também deve primar a correlação das variáveis que podem ser observadas microscopicamente. Somente a forma das trabéculas, pode ser um fator determinante, porém deve relacionar-se com os outros aspectos derivados do estudo do tecido conjuntivo fibroso e do tecido mineralizado.

Alguns autores propõem $(1,8,66$, 70) uma posição unificadora destas lesōes, porém, nossos resultados indicam que apesar de terem características comuns ou compartilhadas, há modalidades delas que permitem seguir investigando estas particularidades no sentido de esclarecer aspectos de sua natureza e comportamento biológico.

\section{CONCLUSÕES}

1. Utilizando métodos histométricos foi possivel estabelecer diferenças histológicas significativas entre a Displasia Fibrosa, o Fibroma Ossificante e o Fibroma Cementificante.

2. Se observou que todos os parâmetros utilizados neste trabalho, se apresentam nas três lesões consideradas. Alguns deles variam em sua importância como elemento para estabelecer um diagnóstico diferencial.

3. As variáveis histológicas mais confiáveis para discriminar entre as três lesões é a forma das trabé- culas do tecido mineralizado. A Displasia Fibrosa apresenta um maior número de trabéculas em "caracteres chineses", o Fibroma Ossificante de trabéculas retangulares e o Fibroma Cementificante de "cementículos".

4. Na Displasia Fibrosa se observa que o indice de fragilidade capilar é mais alto, porém a maior vascularização se encontrou nos casos de Fibroma Ossificante.

5. O Fibroma Ossificante apresentou uma maior diferenciação das células do tecido conjuntivo em osteoblastos que as outras lesōes.

6. Na Displasia Fibrosa foram encontrados osteoblastos no contorno das trabéculas, diferindo do proposto por alguns autores.

7. 0 Fibroma Cementificante apresentou uma maior área de matriz orgânica não mineralizada, com escassa quantidade de células em seu inferior.

8. A celularidade do tecido fibroso demonstrou diferenças entre a Displasia Fibrosa, o Fibroma Ossificante e o Fibroma Cementificante, porém estas variáveis não podem ser usadas no diagnóstico de lesões isoladamente, devido a variabilidade com que se apresentou nas três lesões.

\section{REFERÊNCIAS BIBLIOGRÁFICAS}

1. ADEKEYE, E.O. et al - Fibro Osseous lesions of the skull, face and jaws in Kaduna, Nigeria. Brit. J. Oral Surg., 18:57, 1980.

2. ALBRIGHT, F. et al - Syndrome Characterized by osteitis fibrosa disseminata, areas of pigmentation and endocrine disfunction with precacoceous puberty in females. New. Eng. J. Med. 216:727, 1937.

3. ALEO, J.J. \& VANDERSALL, D.C. - Cementum recent concepts related to periodontal disease therapy. Dental Clinics Northamerica 24(4):627, 1980.

4. ALEXANDER, R.W. - Diagnostic electron microscopy of bone. In: Diagnostic Electron Miroscopy. John Miley \& Sons. 1983, Vol. 4:115-24p.

5. ALLEN, A. et al - statistical Analisis System (SAS) User's Guide: Basic SAS Institute Inc. Cary, North Carolina 27511, 1982 Ed.

6. BARROS, R.E. et al - Displasia Fibrosa Monostótica, Fibroma Osificante y Cementoma. Rev. Assoc. Odontol. Argentina 52:117, 1964.
7. BATSAKIS, J.G. - Tumors of the Head and Neck. 2.ed. William Wilkins, London, 1980.

8. BLAYNEY, A.W. \& EL TAGEB, A.A. The "Hibrid" fibro-osseous lesion. The J. of Laryngology and Otology. $100291,1986$.

9. BORDIN, S. et al - Fibroblast Subtypes in the periodontiun. A possible role in connective tissue regeneration and periodontal reattachement. J. of Periodontal Research 19:642, 1984.

10. BORELLO, C.L. y SEDANO, H.O. - Giant Osteoid Osteoma of the maxila. Oral Surg. 23:563, 1967.

11. BORGES TELES, J.C. - Tumores Odontogenicos de Origen Mesodermico. In: Ebling, H. et al: Cistos e Tumores Odontogenicos. 3.ed. Mc Graw-Hill Brasil, Porto Alegre, 1977, 145-160p.

12. BRADY, C.L. y BOWNE, R.M. - Benign osteoblastoma of the mandible. Cancer, 30:329, 1972.

13. CANNON, J.S. et al - Gigantiform cementoma. Report of two cases (mother and son). J. Oral Surg. 38:65, 1980.

14. DE ROQUANCOURT, A. et al - Kyste aneurysmal mandibulaire associé a un fibrome cementifiant. Une observation. Rey. Stomatol. Chir. Maxillofac. 85(4):325, 19854.

15. EBLING, H. et al - Lesões de células gigantes dos maxilares possibilidades e limitaçōes do diagnóstico histológico. Rev. Fac. Odont. P.A. 12:51, 1970.

16. EL DEEB, M. et al - Aneurysmal bone cyst of the jaws. Report of a case associated with, Fibrous Dysplasia and review of the Literature. Int. J. Oral Surg. 9:301, 1980.

17. ESGUEP, A, et al - Benign Cementoblastoma. Report of an atypical case. J. Oral Med. 38(3):99, 1983.

18. EVERSOLE, L.R. et al - Fibrous Dysplasia: a nosologic problem in the diagnosis of fibro-osseous lesions of the jaws. J. Oral Path. 1:189, 1972.

19. EVERSOLE, L.R. et al - Ossifying Fibroma. A clinico-pathologic. Study of sixtyfour cases. Oral Sug. 60(5):505, 1985.

20. FRANKLIN, C.D. et al - Quantitative Evaluation of normal hiperplastic and premalignant epithelium by stereological methods. In: Mackenzie I.A. et al: Oral Premalignancy, 1.ed. Univ. of lowa, 1980, 242-261p.

21. FREEMAN, E. \& TEN CATE, A.R. - Development of periodontium An Electron Microscopy Study. J. Periodont. 42:387, 1971.

22. FREEMAN, E. Periodontium: In: Ten Cate, $A_{0} R_{0}$ - Histology: Development, Structure and Function, 2.ed. C.V. Mosby, St, Louis, 1985, 234-263p.

23. FRIES, J.W. - The roendgen features of fibrous displasia of the skull and facial bones. Am. J. Roedng. 77:71, 1957.

24. FULLMER, H.M. et al - Oxitalan connective tissues fibers: A review. J. Oral Path. 3:291, 1974.

25. GARDNER, A.F. - Fibrous Dysplasia of the skull with special reference to the oral regions. The Dental Pract. 13:337, 1963. 
26. HAMNER, J.E. et al - Benign fibro-osseous jaw lesions of periodontal membrane origin. An Analysis of 249 cases. Cancer 22:861, 1968.

27. HAMNER, J.E. \& FULLMER, H.M. - Oxitalan Fibers in Benign Fibro Osseous Jaw Lesions. Arch. of Path. 82:35, 1966.

28. HARRIS, W.H. et al - The natual history of the fibrous dysplasia. J. Bone Joint Surg. 44A:207, 1962.

29. JAFFE, H.L. - Fibrous Dysplasia. In: JAFFE, H.L. - Tumors and tumorous conditions of the bone and joints. Philadelphia, Lea Fabiger, 1958, 117-142p.

30. KEMPSON, R.L. - Ossifying fibroma of long bones a light and microscopic study. Arch. Pathol. 82:218, 1966.

31. KRAMER, H.S. - Benign osteoblastoma of the mandible. Report of a case. Oral Surg. 24:844, 1967.

32. KRAMER, I.R.H. - Basic histopathological features of oral premalignant lesions. In: MACKENZIE I.A. et al - Oral Premalignancy. 1.ed. Univ, of lowa Press, lowa $1980,23-34 p$.

33. KRUTCHKOFF, D.J. \& EISENBERG, E. Lichenoid dysplasia: A distinct histopathologic entity. Oral Surg. 60:308, 1985.

34. LANGDON, J.D. et al - Ossifying fibroma. One disease or six? An analysis of 39 fibro-osseous lesions of the jaws Brit. J. of Oral Surg. 14:1, 1976.

35. LEIVAS, S. al - Métodos Histoquimicos. Depto. de Biología Celular y Genética. Fac. de Medicina, Universidad de Chile, 1.ed., Santiago de Chile, 1982, 14p.

36. LICHTENSTEIN, L. - Polyostotic fibrous dysplasia. Arch. Surg. 36:874-1938.

37. LICHTENSTEIN, L. - Bone Tumors. 5.ed., C.V. Mosby Co. St. Louis, 409-15p., 1977.

38. LICHTENSTEIN, L. \& JAFFE, H.L. - Fibrous Dysplasia of bone. Arch. Path. 33:777, 1942.

39. LÓPEZ, A.M.L. et al - Técnicas de Histologla y Citologla. Depto. de Biología Celular y Genética, Fac. de Medicina, Universidad de Chile, 2.ed., Santiago de Chile, 1982, 36-7p.

40. LUCAS, R.B. - Cementoma. In: LUCAS, R.B. - Pathology of tumors of the oral tissues. 4.ed., Longman Edinburg, 100-108, 1985.

41. LUCAS, R.B. - Fibrous Dysplasia of bone and ossifying fibroma. In: LUCAS, R.B. - Pathology of tumors of the oral tissues,
54. SCHAJOWICZ, F. et al - Histologic typing of bone tumors. Geneva, WHO, 1972.

55. SCHAJOWICZ, F - Displasia Fibrosa. In: SCHAJOWICZ, F. - Tumores y Lesiones seudotumorales de huesos y articulaciones, 1.ed. Panamericana, B. Aires, 1982, 481-92p.

56. SHAFFER, W.G. et al - A text book of oral pathology. 4.ed., Philadelphia, W.B. Saunders, 1983.

57. SLAVKIN, A.C. - Towards a cellular and molecular understanding of periodonticscementogenesis revisted. J. Periodontol. 47(5):249, 1976.

58. SMITH, A.G. \& ZAVALETTA, A. - Osteoma Ossifying Fibroma and Fibrous Displasia of facial and cranial bones. Arch. Path. 54:507, 1952.

59. SMITH, C. and PINDBORG, J.J. - Histological grading of oral epithelial atypia by the use of photographic standards. Copenhagen, 1969.

60. SPJUT, $\mathrm{H}_{\mathrm{a}}$. et al - Tumors of bone and cartilage in Atlas of Human Pathology (AFIP, Washington, D.C. 1971), 260p.

61. STANLEY, K. \& CURRAN, J.B. - Giant cemento ossifying fibroma. J. Oral Surg. 30:513, 1972.

62. SUGIMURA, $M_{0}$ et al - Cementifying fibroma of the maxilla. Report of a case. Int. J. Oral Surg. 10.298, 1981.

63. TEN CATE, A.R. - The Fibroblast and its products. In: TEN CATE, A\&. - Oral Histology: Development structure and function, 2ad., SC.V. Mosby, Co., St. Louis, 1985, 88-100p.

64. TEST, D. et al - Juvenile Ossifying Fibroma. J. Oral Surg. 34:907, 1976.

65. VAN DER WAAL, et al - Benign osteoblastoma or osteoid osteoma of the maxila. Report of a case. In. J. Oral Surg. 12:355, 1983.

66. WALDRON, C.A. - Fibro-osseous lesions of the jaws. J. Oral Surg. 28:58, 1970.

67. WALDRON, C.A. \& GIANSANTI, J.S. Benign fibro-osseous lesions of the jaws. Part. I.: Fibrous dysplasia of the jaws. Oral Surg. 35:190, 1973.

68. WALDRON, C.A. \& GIANSANTI, J.S. Benign fibro-osseous lesions of the jaws. Part. II. - Benign fibro-osseous lesions of periodontal ligament origin. Oral Surg. 35:340, 1973.

69. WALDRON, C.A. et al - Sclerotic cemental masses of the jaws (so called chronic sclerosing osteomyelitis, sclerosing osteitis multiple enostosis and giantiform cementoma). Oral Surg. 39:590, 1975.

70. WALDRON, C.A. - Fibro-osseous Isions of the jaws. J. Oral Maxillo-Fac. Surg. 43:249, 1985.

71. ZACHARIADES, N. et al - Ossifying fibroma of the jaws. Review of the literature and report of 16 cases. Int. J. Oral Surg. 13:1, 1984 .

72. ZIMMERMANN, D.C. et al - Fibrous Dysplasia of maxila and mandible. Oral Surg. 11:55, 1958.

4.ed., Longman Edinburg, 395-407p. 1985.

42. LUNA, L.G. - Manual of Histologic Staining Methods of the Armed Forces Institute of Pathology. 3.ed., Mc Graw-Hill Book Co., New York, 1968, 76p.

43. MADER, C.L. y WENDERLBURG, L. Benign cementoblastoma. J. Am. Dental Assoc, 99:990, 1979.

44. MAKEK, M. - Clinical pathology of fibroosteo-cemental lesions in the craneo-facial and jaw bones. A new approach to diferential diagnosis. Karger Switzerland, 1983.

45. MELROSE, R.J. et al - Florid osseous dysplasia. Oral Surg. 41:62, 1976.

46. MONTGOMERY, A.L. - Ossifying fibromas of jaws. Arch. Surg. 15:30, 1927.

47. MUGNEIER, A. et al - Un cas de tumeur rare du maxillarie: L'osteocementofibrome. Rev. Stomatol. Chir. Maxillofac. 85(5):399, 1984.

48. OSAKI, J.M. et al - Albright's Syndrome involving the facial bone. J. Oral Surg. $39: 227,1981$.

49. PHEMISTER, D.B. \& GRIMSON, K.S. Fibrous Osteoma of the jaws. Ann of Surg. 105:564, 1937.

50. PINDBORG, J.J. et al - Histologic typing of odontogenic tumours jaw, cysts and allied lesions. World Helath Organization, Geneva, 1971.

51. REED, R.J. \& HAGY, D.M. - Benign Non odontogenic fibro-osseos lesions of the skull. Oral Surg. 19:214, 1965.

52. REICHART, P. \& RIES, P. - Considerations on the classifications of odontogenic tumors. Int. J. Oral Surg. 12:323, 1983.

53. RONDANELLI, B. - Estudio anatómo-patológico de las lesiones fibro-óseas de los maxilares, ingresadas en el Servicio de Anatomia Patologica entre los años 1958-1975. Tesis de Grado, Escuela Dental, Universidad de Chile, 1976. 